\title{
The Primary Care Medical Home: Whose Home is It? Reaction to the Paper by Karen Davis, PhD, and Kristof Stremikis, MPP
}

\author{
Erika Bliss, MD
}

In their article titled "Family Medicine: Preparing for a High-Performance Health Care System," Karen Davis and Kristof Stremikis ${ }^{1}$ present an exciting and affirming vision for the future of primary care in this country. Thanks to the wide acceptance of the concept of the medical home among policymakers, health systems, and now some payers, primary care is finally on the map in a serious way. Although health care reform discussions in Washington, D.C., still mainly focus on issues of insurance coverage, there is an increasing emphasis on the important role primary care must play if the system is to deliver on any measures of quality, cost, and access.

There has been excellent progress in various parts of the country in moving toward care that has some or all of the 7 attributes of ideal primary care:

\section{1. superb access to care;}

2. patient engagement in care;

3. clinical information systems;

4. care coordination;

5. integrated, comprehensive care;

6. ongoing, routine patient feedback; and

7. publicly available information about practices.

As aptly stated by Davis and Stremikis, ${ }^{1}$ the United States lags far behind most other industrialized nations on all these measures. However, the energy and leadership provided by those who have been working on the development and promotion of the patientcentered primary care medical home, especially that of the Commonwealth Fund, has created significant momentum that we must continue to feed.

Nonetheless, there is a fundamental flaw in this and other movements for health care reform. Although we all talk about patient-centered care, the

From Qliance Medical Management, Inc., Seattle, WA.

Funding: none.

Conflict of interest: none declared.

Corresponding author: Erika Bliss, MD, Qliance Medical Management, Inc., 509 Olive Way, Suite 1607, Seattle, WA 98101 (E-mail: ebliss@qliance.com). care is still designed, implemented, and controlled by those inside the health care system and the insurance companies, employers, and government bodies that pay for it. The patient is still mainly an afterthought, an object of the system rather than an active participant, generator of ideas, or source of pressure for change. Where participation is present, it is usually in the context of inviting the patient to participate in implementing the care plan that the system has determined is right for them. Although patient satisfaction surveys are important feedback for practices and health care systems, many of them do not ask the kind of questions that would get at whether the system is even designed to meet patients' needs in the first place.

One of the most serious problems we have in this country with regards to moving toward a truly patient-centered system is that patients have no power within the system. They do not even really pay directly for their own care, whether using their own dollars or those of others. In fact, it is very difficult to pay directly for care. It is hard to obtain "cash" pricing from any health care provider up front before the service is delivered, and when "cash" pricing is provided, it is usually grossly inflated and reflects the "retail" price that is used as a starting point in negotiations between health care providers and payers. It is then up to the patient to negotiate for a discount, which they often do not even know they can do.

Coverage is not very portable, and patients cannot easily vote with their feet (and dollars) when they are unhappy with quality, access, or service. The best they can do is take their insurance and determine whether they can find another provider who honors their plan and then hope that the care is better. Insurance companies are under pressure by state insurance commissioners to maintain "network adequacy" and are therefore unlikely to drop low-performing providers in response to patient complaints. In some cases, like with people receiving Medicaid or Medicare, the number of providers accepting payment by those programs is shrinking or is already very small, so patients 
have even less choice and therefore less power. They do not even have any control over their own medical record, which is dispersed across many institutions in many different formats and is difficult to access. In fact, many practices charge the patient for copies of their record while simultaneously providing free copies to other medical providers.

Clearly, to have any kind of meaningful health care reform everyone must have coverage and be relieved of the stress and risk to which they are exposed in the current patchwork system. If primary care is going to work, it must be funded more robustly, a point that is underscored by Davis and Stremikis ${ }^{1}$ in their statement that most of the practices engaged in reform toward a medical home model benefit from extensive support in the form of financial payments, technical assistance, and/or inkind assistance. They simply cannot do it on the current budget of $\$ 200$ to $\$ 250$ per capita per year spent on primary care in the United States.

But what about the patient (who, by the way, is also us when we are sick and need care)? What about giving every American direct purchasing power? Many health care thinkers and policymakers are afraid of unleashing unfettered consumer demand on the health care system, assuming that there will be overwhelming demand for expensive and unproven treatments that will break the bank. But we could start small with primary care alone, which is low cost, low risk, and fairly circumscribed in the scope of services that can be offered (ie, primary care providers will never do bone marrow transplants or major surgery). What if we gave every person in the country between $\$ 500$ to $\$ 600$ per year to spend on primary care, less than one tenth of the current per capita spending on health care, then let them take that money and spend it on the primary care services they feel best meet their needs? If they do not like what they get or feel that they are not getting full value, they can pick up and move to another primary care provider at any time without penalty. This would quickly introduce some bottom-up pressure on primary care providers to change the way they operate and to provide services that are truly responsive to the needs of their community. If fee-for-service office visits are what people want, some providers can offer those. If capitated, monthly, all-inclusive care is what people want, others can offer this option. If home-based care is what people want, physicians can offer that, and so on. Practices would be directly accountable to the people they serve and would have to compete with each other for business; this would drive much more rapid innovation and improvements. They would also have to make their pricing transparent and provide that information before the service is provided, something that is expected of all other businesses. And compared with the measly dollars currently allocated to primary care, $\$ 500$ to $\$ 600$ per year would instantly inject financial stability into a faltering primary care system that is failing both itself and the people it is supposed to serve.

Another important step would be to start moving immediately toward patient-controlled medical records. It is no longer acceptable, from the perspectives of privacy, safety, and cost, to have patients' records strewn across the landscape and out of their reach. The Federal government has an opportunity to move things in this direction by requiring that, as a condition of funding, all patient records be interoperable and patient-controlled by a certain date in the future. Taiwan has already figured this out; they use a smart card with complete records to which patients give their providers access when they present for care. Certainly the United States could come up with some kind of even more innovative system of recordkeeping that would protect privacy, prevent duplication, and give patients access to and control of their health information while also allowing for analysis of aggregate data for evaluation of system performance and public health issues. This would also help us provide to patients greater transparency of information about quality and performance so that they could make more informed decisions about their care.

Although giving patients direct purchasing power and control of their medical records would not solve all of our system's woes, it has the potential to fire up the best of American ingenuity in solving problems and bringing ever-better products and services to the marketplace. What better place to start than in primary care? Why not tackle the fundamentals, creating payment and information systems that, by definition, make us accountable to our patients and that inject the capital needed for practices to make rapid change? We, both as providers and as patients, would thank ourselves for it.

\section{Reference}

1. Davis K, Stremikis K. Family medicine: preparing for a high-performance health care system. J Am Board Fam Med 2010;23(Suppl):S11-6. 